\title{
Erratum to: Nurse Practitioners and the Performance of Professional \\ Competency: Accomplishing \\ Patient-centered Care
}

Staci Defibaugh

Erratum to:

S. Defibaugh, Nurse Practitioners and the Performance of Professional Competency: Accomplishing Patient-centered Care, Communicating in Professions and Organizations, https://doi.org/10.1007/978-3-319-68354-6

An error in the production process led to the publication of this book prematurely, before the incorporation of some corrections. Extracts and their in-text references have been updated and the corrected version has been approved by the author.

The updated online version of this book can be found at https://doi.org/10.1007/978-3-319-68354-6

(C) The Author(s) 2018

E1

S. Defibaugh, Nurse Practitioners and the Performance of Professional

Competency, Communicating in Professions and Organizations, https://doi.org/10.1007/978-3-319-68354-6_7 